\title{
Adsorption of arsenic by birnessite-loaded biochar in water and soil
}

\author{
H.Y. Wang, P. Chen \& G.-X. Sun \\ State Key Laboratory of Urban and Regional Ecology, Research Center for Eco-Environmental Sciences, \\ Chinese Academy of Sciences, Beijing, P.R. China
}

\begin{abstract}
A novel biochar was successfully prepared through modification of birnessite to improve its capability to adsorb As in water and soil. The saturated adsorption capabilities of birnessite-loaded biochar (BRB) for As(III) and As(V) were as large as 3621 and $2381 \mathrm{mg} \mathrm{kg}^{-1}$ (calculated by Langmuir isotherm model), much higher than for the corresponding non-loaded biochar (no sorption of As). In comparison with control, after 6 weeks' incubation in contaminated soil, BRB showed potential for reducing As concentration under flooded condition in pore water, respectively. These results suggested that BRB could be used as an effective sorbent for simultaneous immobilization of heavy metals, especially As in environmental and agricultural systems.
\end{abstract}

\section{INTRODUCTION}

Adsorption is one of the most commonly used methods for removal of arsenic (As) from the aqueous phase or for immobilization of them in soil because of their non-degradable properties and tendency for bio-accumulation in the food chain. Biochar has few or no sorption abilities for anionic forms such as As, or even enhanced reduction and release of As from soil because of the increase in organic matter and $\mathrm{pH}$ in the soil after biochar addition (Beesley et al., 2011).

Several studies have reported on the modification of biochars to enhance their sorption abilities for As from aqueous solutions. Birnessite is one of most abundant manganese $(\mathrm{Mn})$ oxides in terrestrial environments, and many studies have noted its high sorption capabilities for As. Biochar can provide an effective surface for birnessite coating and might be a promising media for increasing As removal. In this work, we speculated that biochar could be loaded with birnessite and that this environmentally friendly material could be a suitable adsorbent for simultaneously removing As from aqueous solutions or immobilizing both of them in soils. The sorption mechanism of As by birnessite was unclear.

The objectives of this work were to: (1) prepare and characterize the birnessite-loaded biochar; (2) explore the capabilities and mechanisms of birnessite-loaded biochar for sorption of $\mathrm{As}(\mathrm{As}(\mathrm{V})$ or $\mathrm{As}(\mathrm{III}))$.

\section{METHODS/EXPERIMENTAL}

\subsection{Preparation of birnessite-loaded rice husk biochar}

Rice husk was pyrolyzed in a muffle furnace under an $\mathrm{N} 2$ environment by holding the peak temperature at $600^{\circ} \mathrm{C}$ for $4 \mathrm{~h}$. Unloaded rice husk biochar (RB) was used as the control.
Birnessite was loaded onto RB using the $\mathrm{KMnO}_{4}$ precipitation method described by McKenzie (1971) and Feng (2007) and designated as BRB. Biochar $(10 \mathrm{~g})$ was added to the $\mathrm{KMnO}_{4}$ solution $(0.4 \mathrm{M}$, $100 \mathrm{~mL}$ ) and stirred for $2 \mathrm{~h}$, then boiled for $20 \mathrm{~min}$, followed by drop addition of $6.6 \mathrm{~mL}$ concentrated $\mathrm{HCl}$ as reducer at the rate of $0.7 \mathrm{~mL} \mathrm{~min}^{-1}$, then boiled for another $10 \mathrm{~min}$. The resulting biochar-birnessite composites were rinsed thoroughly with deionized water, then oven dried at $60^{\circ} \mathrm{C}$ for about $12 \mathrm{~h}$.

\subsection{Sorption kinetics for $C d, A s(I I I)$ and $A s(V)$}

Sorption kinetics of As(III) $\left(5 \mathrm{mg} \mathrm{L}^{-1}\right)$, As(V) $(6 \mathrm{mg}$ $\left.\mathrm{L}^{-1}\right)$, and $\mathrm{Cd}\left(26 \mathrm{mg} \mathrm{L}^{-1}\right)$ by BRB were investigated. Briefly, BRB $(0.05 \mathrm{~g})$ was added into $10 \mathrm{~mL}$ of sorbate solutions (As(III), As(V)) in $15 \mathrm{~mL}$ centrifuge tubes at room temperature $\left(25^{\circ} \mathrm{C}\right)$, with $0.01 \mathrm{~mol} \mathrm{~L}^{-1} \mathrm{Cen}$ trifuge tubes containing the BRB and solutions were placed onto a rotary shaker and shaken at $150 \mathrm{rpm}$. At each sampling time $(1,2,4,8,12,24,48 \mathrm{~h})$, three replicates were taken out and immediately filtered through $0.45 \mu \mathrm{m}$ nylon membrane filters. The concentrations of $\mathrm{As}(\mathrm{III})$ and $\mathrm{As}(\mathrm{V})$ in supernatants were determined using ICP-OES or ICP-MS. The initial $\mathrm{pH}$ values of the solutions were adjusted to $6.0 \pm 0.2$ with $0.01 \mathrm{~mol}$ $\mathrm{L}^{-1} \mathrm{HCl}$ or $\mathrm{NaOH}$.

\section{RESULTS AND DISCUSSION}

\subsection{Characterization of $B R B$}

Compared with RB, RB loaded with birnessite resulted in more than $2 \times$ higher pore volume than unmodified $\mathrm{RB}$, while the BET surface area decreased by more than two thirds, indicating that birnessite changed the pore size distribution of the RB. The SEM image of $\mathrm{BRB}$ was different from that of $\mathrm{RB}$, with randomly 


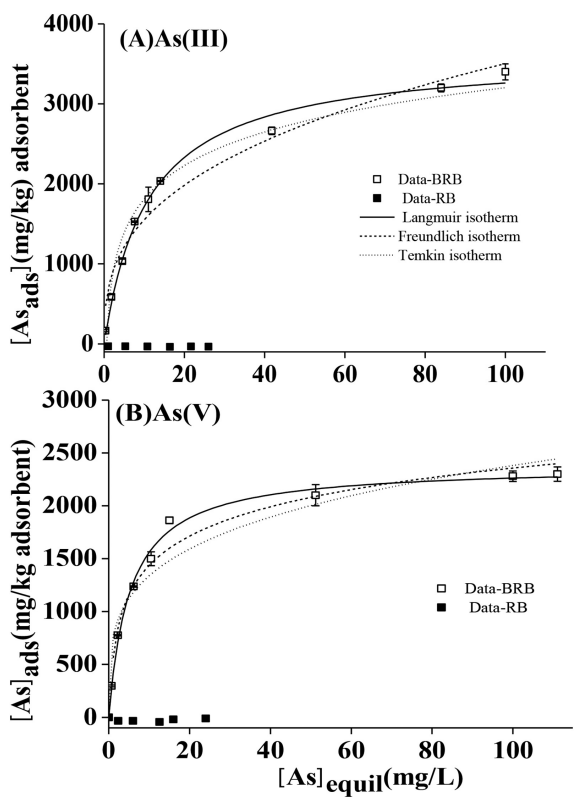

Figure 1. As(III) (A) and $\mathrm{As}(\mathrm{V})(\mathrm{B})$ sorption isotherm and fitted models for BRB.

stacked birnessite on the surface of the BRB; the poorly crystallized birnessite was further confirmed by XRD analysis. The XPS wide-scan spectra of BRB showed a substantial increase in Mn content compared with the wide-scan spectra of RB.

\subsection{As(III), As $(V)$ and $C d$ sorption kinetics and isotherms}

$\mathrm{As}(\mathrm{III})$ and $\mathrm{As}(\mathrm{V})$ sorption onto BRB were biphasic, with a rapid initial phase over the first few hours followed by a much slower sorption phase, indicating that more than one mechanism affected the sorption processes. Pseudo-first-order, pseudosecond-order, and Elovich models were tested for their abilities to simulate the sorption kinetics data. The results showed that the pseudo-second-order kinetic model was better than the pseudo-first-order model for describing all data $\left(\mathrm{R}^{2}>0.92\right)$, indicating that binuclear adsorption was dominant. The Elovich model, an empirical equation, was the best to describe kinetic data with coefficients of correlation $\left(\mathrm{R}^{2}\right)$ above 0.96 . Based on the adsorption isotherm, BRB exhibited superior abilities to adsorb $\mathrm{As}(\mathrm{III})$ and $\mathrm{As}(\mathrm{V})$ and the maximum sorption capacities obtained from the Langmuir model were $3621 \mathrm{mg} \mathrm{kg}^{-1}$ for As(III) and $2381 \mathrm{mg} \mathrm{kg}^{-1}$ for As(V), while RB had no ability to adsorb As (Fig. 1). The sorption capacity of BRB was much higher for As(III) than for $\mathrm{As}(\mathrm{V})$, probably because the oxidation of As(III) by synthetic birnessite was accompanied by $\mathrm{Mn}(\mathrm{II})$ and $\mathrm{As}(\mathrm{V})$ release, and dissolution of $\mathrm{Mn}$ (II) created more fresh reaction sites for $\mathrm{As}(\mathrm{V})$ on birnessite surfaces.

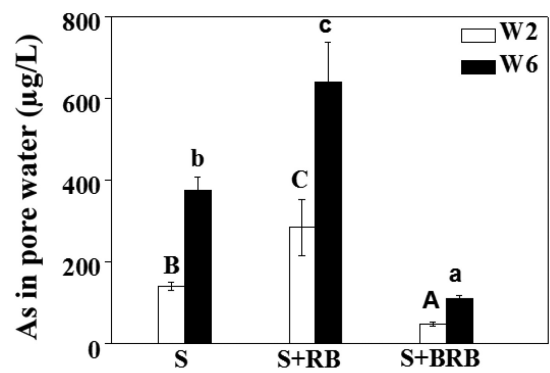

Figure 2. Concentrations of As in pore water of the treatment of soil $(\mathrm{S})$, soil + rice husk char $(\mathrm{S}+\mathrm{RB})$, soil + birnessite-loaded rice husk biochar $(\mathrm{S}+\mathrm{BRB})$ under and flooded condition in the second week (W2) and sixth week (W6).

\subsection{Application of BRB in soil under flooded conditions}

The As concentration in pore water of the control increased by 1.7 times from week 2 to week 6 . At W6, the As concentration in the BRB treatment $(111 \mu \mathrm{g}$ $\mathrm{L}^{-1}$ ) was 5.76 -fold lower than that in the RB treatment and 3.39-fold lower than in the control treatment (Fig. 2). This experiment suggests that the application of BRB could effectively reduce the As bioavailability in soil under flooded conditions.

\section{CONCLUSIONS}

A novel biochar was prepared by modification with birnessite. Birnessite-loaded biochar enhanced its ability to remove As from aquatic solution and soil and exhibited a hybrid adsorption property to simultaneously remove As and $\mathrm{Cd}$. These results suggested that birnessite-loaded biochar has potential for remediation of heavy metal contaminated water and soil, especially in the case of multi-metal contamination.

\section{ACKNOWLEDGEMENTS}

This project was financially supported by the Natural Science Foundation of China (No. 41371459), the State Key Program of Natural Science Foundation of China (No. 41330853, 41430858).

\section{REFERENCES}

Beesley, L., Jiménez, E.M., Gomez-Eyles, J.L., Harris, E. Robinson, B. \& Sizmur, T. 2011. A review of biochars' potential role in the remediation, revegetation and restoration of contaminated soils. Environ. Pollut. 159(12): 3269-3282.

Feng, X.H., Zhai, L.M., Tan, W.F., Liu, F. \& He, J.Z. 2007. Adsorption and redox reactions of heavy metals on synthesized Mn oxide minerals. Environ. Pollut. 147(2): 366373.

McKenzie, R.M. 1971. The synthesis of birnessite, cryptomelane, and some other oxides and hydroxides of manganese. Mineral. Mag. 38(296): 493-502. 